\title{
Proceeding
}

Supplementary Issue: Spring Conferences of Sports Science. Costa Blanca Sports Science Events, 19-20 June 2020. Alicante, Spain.

\section{Evaluation of Orexin-A serum levels in karate athletes cohort}

\author{
GIOVANNI MESSINA ${ }^{1}$, ANTONIETTA MESSINA ${ }^{2}$, VINCENZO MONDA ${ }^{2}$, ALBERTO AMETTA ${ }^{3}$, \\ FRANCESCO SESSA ${ }^{1}$, VINCENZO CRISTIAN FRANCAVILLA ${ }^{4}$, AURORA DANIELE ${ }^{5}$, MARCELLINO \\ MONDA $^{3}$, RITA POLITO 1 \\ ${ }^{1}$ Department of Clinical and Experimental Medicine, University of Foggia, Italy \\ ${ }^{2}$ Department of Economy, University of Foggia, Italy \\ ${ }^{3}$ Department of Experimental Medicine, Section of Human Physiology and Unit of Dietetic and Sport Medicine, \\ University of Campania Luigi Vanvitelli, Naples, Italy \\ ${ }^{4}$ School of Engineering, Architecture, and Motor Sciences, Kore University of Enna, Enna, Italy \\ ${ }^{5}$ Department of Biological and Pharmaceutical Environmental Sciences and Technologies, University of Campania \\ Luigi Vanvitelli, Naples, Italy
}

\begin{abstract}
The lateral hypothalamus products various neuropeptides, among of these the Orexin-A (hypocretin-1) is a protein that regulates numerous physiological and behavioural processes involving in energy balance and metabolic status, physical activity, blood glucose levels, and food intake. Many data literature reported that the production of Orexin-A increases following regular and structured physical activity. Indeed, it improves energy metabolism and insulin sensitivity, and also modulate energy expenditure and thermogenesis. The higher Orexin-A tone is an endogenous factor that predicts physical activity, improving BMI and the energy expenditure aspect. It is well known that physical activity has positive effects on health and body weight, it improves cognitive performance increasing Orexin-A levels. Given these evidences, the aim of this study is evaluated Orexin-A serum levels in a cohort of karate athletes. Fort these reasons, were recruited 10 young karate athletes and 10 matched non-athletes as control. We evaluated biochemical and anthropometric parameters, and Orexin-A serum levels through ELISA-test. Our results showed that there is a statistical difference between karate athletes and non-athletes in BMl and in biochemical parameters such as glycaemic and lipid profile. Interestingly, Orexin-A serum levels are statistical higher in karate athletes compared to non- athletes. The differences between athlete and non-athletes in this study could be attributed to a better trainingrelated hypothalamic activity in karate athletes. In addition, these evidences indicate that the physical activity has beneficial effects not only on anthropometric and biochemical parameters but also on orexin-A levels, and then on central nervous system.

Keywords: Orexin-A; Central nervous system; Karate athletes; Physical activity.

Cite this article as:

Messina, G., Messina, A., Monda, V., Ametta, A., Sessa, F., Francavilla, V.C., Daniele, A., Monda, M., \& Polito, R. (2020). Evaluation of Orexin-A serum levels in karate athletes cohort. Journal of Human Sport and Exercise, 15(3proc), S781S786. doi:https://doi.org/10.14198//hse.2020.15.Proc3.28

Corresponding author. Department of Clinical and Experimental Medicine, University of Foggia, Italy.

E-mail: giovanni.messina@unifg.it

Supplementary Issue: Spring Conferences of Sports Science. Costa Blanca Sports Science Events, 19-20 June 2020. Alicante, Spain.

JOURNAL OF HUMAN SPORT \& EXERCISE ISSN 1988-5202

(c) Faculty of Education. University of Alicante

doi:10.14198/jhse.2020.15.Proc3.28
\end{abstract}




\section{INTRODUCTION}

Orexin-A/Hypocretin 1, is a neuropeptide synthesized in the lateral hypothalamus (Messina et al., 2016; Sperandeo et al., 2018). It plays an important role in the regulation of appetite, in addition several studies reported that an intracerebroventricular injection of Orexin-A modifies eating behaviour, increasing heart rate, blood pressure, and metabolic rate (Chieffi et al., 2017a; Inutsuka and Yamanaka, 2013a; Messina et al., 2015). Orexin-A is involved also in stimulation of food intake, hunger and hypoglycaemia, it plays an important role in the regulation of metabolic status (Messina. et al., 2014; Messina et al., 2018). Orexin-A modulates energy metabolism, excitement, and physical activity, playing a pivotal role fighting obesity, increasing physical activity, and thermogenesis during non-exercise activities, as well as energy expenditure (Sakurai, 2014). In mouse model studies show that the injection of Orexin-A in the lateral hypothalamus induced weight loss, developing a greater propensity for spontaneous physical activity, increasing energy expenditure and diminishing food intake (Clark et al., 2009; Diniz Behn et al., 2010; España et al., 2007). Also, in human Orexin-A as many beneficial effects, on metabolic status reducing glycemia and modulating lipid profile, and also stimulating spontaneous physical activity. Many data literature reported that the production of Orexin-A increases following regular and structured physical activity. Indeed, it improves energy metabolism and insulin sensitivity, and also modulate energy expenditure and thermogenesis. The higher Orexin-A tone is an endogenous factor that predicts physical activity, improving BMI and the energy expenditure aspect. It is well known that physical activity has positive effects on health and body weight, it improves cognitive performance increasing Orexin-A levels. Karate is one of the most popular martial arts practiced worldwide. Karate contains two main practices (i.e., kata and kumite). Kata represents a demonstrating pre-arranged form of methods of defence, attack, and counterattack. In this training, a performance of set sequences of basic techniques in a fight with an imaginary opponent is performed. Kumite represents the process of sparring utilizing karate skills performed by two opponents. Kumite requires the karateka, a rapid choice of the adequate action pattern to defence and attack (Moscatelli et al., 2016). High technical skills (i.e., kick and punch)are required in fight (i.e., kumite) and high levels of precision and velocity are needed to execute the right movements for attack and defence (Moscatelli et al, 2016). In addition, cognitive abilities and efficient attentional processes influence the technical performance in karate allowing more time for the organization of motor behaviour; furthermore, quick and correct responses are ensured to visuospatial stimuli (Moscatelli et al., 2016) Given these evidences, the aim of this study is evaluated Orexin-A serum levels in a cohort of karate athletes (Catenacci and Wyatt, 2007; Cox, 2017; Monda et al., 2019) showing the beneficial effects of physical activity has beneficial effects not only on anthropometric and biochemical parameters but also on orexin-A levels, demonstrating the important role of central nervous system in karate athletes.

\section{MATERIAL AND METHODS}

10 karate athletes and10 matched non-athletes were recruited All procedures were conformed to the directives of the Declaration of Helsinki and were approved by the Institutional Ethical Committee of the University of Foggia. The athletes were Caucasian karate black belts. They competed at national and international levels; they trained at least five 2-h sessions every week during the previous 5 years. Fasting blood samples were collected at 8:00 am from an antecubital vein, using a 21G Vacutainer blood collection set (BD Diagnostics, Franklin Lakes, NJ, USA). Blood samples were centrifuged and the resultant serum stored at $-80^{\circ} \mathrm{C}$, until use.

\section{Biochemical assay}

As previously described serum orexin-A concentrations were determined by enzyme-linked immunoassay (ELISA), using a commercial kit, according to manufacturers' instructions (Phoenix Pharmaceuticals, USA). 
Briefly, Sep-Pak C18 columns (Waters, Milford, MA, USA) were utilized to extract orexin-A from karate athletes and non- athletes. (Valenzano et al, 2019).

\section{Statistical analysis}

Statistical analyses were performed using the StatView software 5.0.1.0. All data are presented as mean \pm SE. A $p$ value of $\leq .05$ was used for statistical significance.

\section{RESULTS}

We found a significant difference between karate athletes and non-athletes subjects. In particular, as show Table 1, karate athletes have a better anthropometric and biochemical profile (Table 1). Furthermore, there is a strongly modulation of all biochemical parameters, such as glycaemic and lipid profile. Interestingly, as show ELISA test Orexin-A levels in karate athletes is statistical higher compared to non-athletes subjects (Figure 1).

Table 1. Anthropometric and biochemical parameters of karate athletes vs non-athletes.

\begin{tabular}{lll}
\hline & Non-athletes (10) & Karate Athletes (10) \\
\hline Age & $27.9 \pm 1.5$ & $28 \pm 2.5$ \\
BMl & $25 \pm 4.5$ & $23.3 \pm 3.5^{* *}$ \\
Total Cholesterol & $170 \pm 9$ & $159 \pm 8.7^{* *}$ \\
LDL (mg/dL) & $110 \pm 5.4$ & $90 \pm 3.7^{* *}$ \\
HDL (mg/dL) & $54 \pm 2$ & $56 \pm 2.8$ \\
Triglycerides (mg/dL) & $95 \pm 2.3$ & $89 \pm 3.5$ \\
Glucose $(\mathrm{mg} / \mathrm{dL})$ & $97 \pm 6.5$ & $79 \pm 5.5^{* *}$ \\
\hline \multicolumn{2}{c}{ Note: ${ }^{* *} p$-value $<.05}$.
\end{tabular}

\section{OREXIN -A pg/ml}

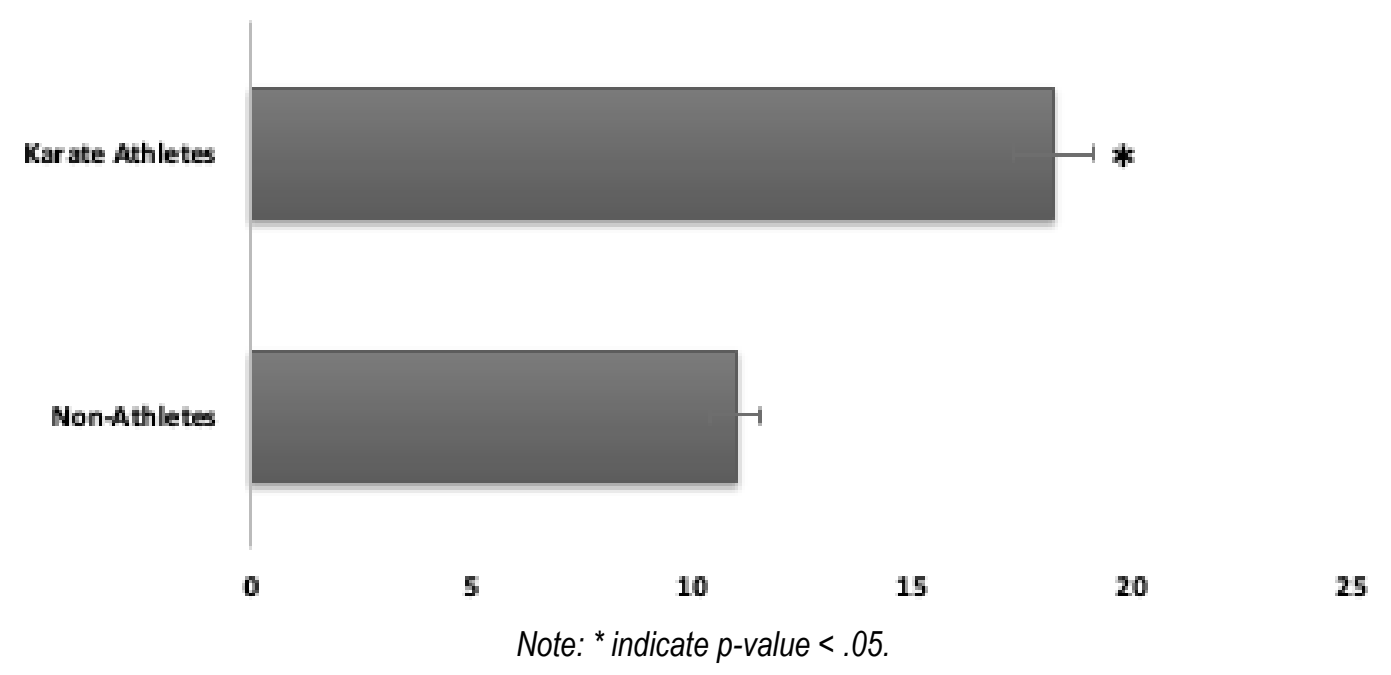

Figure 1. Orexin-A serum levels statistical higher in karate athletes compared to non-athletes subjects. 


\section{DISCUSSION}

Karate is one of the most popular martial arts practiced worldwide. Karate contains two main practices. This sport is composed by physical and cognitive factors. Indeed, are required technical skills and high levels of precision and velocity. In addition, the performance may be influenced by cognitive abilities and efficient attentional processes (Bianco et al, 2018; Francavilla et al, 2017; Messina A. et al, 2018; 2017; 2016; Sessa et al., 2018). Also, it is well know that the physical exercise protects against cardiovascular, bone and joint, and metabolic disorders such as diabetes and that it is an effective means in the prevention and treatment of certain types of cancer (Francavilla C et al,2013, Francavilla et al, 2015; Messina G. et al 2015; Monda et al., 2019; Penna et al, 2019; Patti et al., 2017).

The physical activity has numerous beneficial effects, on cardiovascular performance and protects against many preventable diseases. In addition, during physical activity, there are some physiological adaptations that induced the production of important mediators such as Orexin-A. This neuropeptide is synthesized in the lateral hypothalamus (Messina et al, 2016; Eyman et al., 2013; Gonzalez et al., 2012). It has numerous beneficial effects on insulin sensitivity, energy expenditure and metabolic rate and is involved in immune processes and then regulate inflammatory response, with an anti- inflammatory action (Sperandeo et al, 2018, Monda et al, 2019; Giuditta et al, 2013; Moscatelli et al., 2015). In the light of these evidences, in this study we evaluated Orexin-A serum levels in a cohort of karate athletes compared to non-athletes. We found a strong difference in anthropometric and biochemical parameters between karate athletes and non-athletes subjects. In particular, a better glycaemic and lipid profile in athletes confirm the beneficial effects of physical activity (Cavaliere et al., 2019; 2018; Francavilla et al., 2018; Spagnolo et al., 2019; Ventura et al., 2018; Mondello et al., 2018). Also, the higher Orexin-A serum levels in karate athletes compared non-athletes subjects show the cognitive response induced by physical activity. Indeed as reported by Polito et al, the physical activity has positive effects on health and body weight and also it improves cognitive performance acting on Orexin-A production (Polito et al 2020, Colcombe et al., 2004, 2006; Erickson et al., 2011; Lindwall et al., 2008; Mazzeo et al., 2013; Sapienza et al, 2017; Gualniera et al., 2017; Maio et al., 2020).

Therefore, orexin signalling might positively regulate feeding and arousal, but also motor activity and basal energy expenditure, resulting in resistance to weight gain (Vicchio et al., 2020; Guarnieri et al., 2020; Viggiano et al., 2009; 2016; Francavilla et al, 2007; 2018; 2016). Furthermore, the Orexin-A level is correlated with physical activity and low sedentary time. Higher Orexin-A tone is an endogenous factor that predicts physical activity, improving BMI and energy expenditure. In conclusion these evidences indicate that the physical activity has beneficial effects not only on anthropometric and biochemical parameters but also on orexin-A levels, and then on central nervous system. In addition, the Orexin-A may be beneficial cognitive effects in karate sport but further studies are needed to clarify this action.

\section{REFERENCES}

Cavaliere G, Trinchese G, Penna E, Cimmino F, Pirozzi C, Lama A, Annunziata C, Catapano A, Mattace Raso G, Meli R, Monda M, Messina G, Zammit C, Crispino M, Mollica MP. High-Fat Diet Induces Neuroinflammation and Mitochondrial Impairment in Mice Cerebral Cortex and Synaptic Fraction. Front Cell Neurosci. 2019 Nov. 12;13:509. https://doi.org/10.3389/fncel.2019.00509

Cavaliere G, Viggiano E, Trinchese G, De Filippo C, Messina A, Monda V, Valenzano A, Cincione RI, Zammit C, Cimmino F, Catapano A, Sessa F, Messina G, Monda M, Crispino M, Mollica MP. Long Feeding High-Fat Diet Induces Hypothalamic Oxidative Stress and Inflammation, and Prolonged 
Hypothalamic AMPK Activation in Rat Animal Model. Front Physiol. 2018 9:818. https://doi.org/10.3389/fphys.2018.00818

Chieffi, S., Carotenuto, M., Monda, V., Valenzano, A., Villano, I., Precenzano, F., et al. (2017a). Orexin system: The key for a healthy life. Front. Neurol. 8. https://doi.org/10.3389/fphys.2017.00357

Cristian V Francavilla, Francesco Sessa, Monica Salerno, Giuseppe D Albano, Ines Villano, et al. Influence of Football on Physiological Cardiac Indexes in Professional and Young Athletes. Front Physiol. 2018; 9:153. https://doi.org/10.3389/fphys.2018.00153

Francavilla VC, Bongiovanni T, Genovesi F, Minafra P, Francavilla G. Localized bioelectrical impedance analysis: how useful is it in the follow-up of muscle injury? A case report. MED SPORT 2015; 68:32334.

Francavilla C, Bongiovanni T, Todaro L, Genovesi F, Francavilla G. Risk factors, screening tests and prevention strategies of muscle injuries in elite soccer players: a critical review of the literature. Med Sport 2016; 69: 134-50.

Francavilla VC, Bongiovanni T, Todaro L, Di Pietro V, Francavilla G. Probiotic supplements and athletic performance: a review of the literature. MED SPORT 2017; 70: 000-000. https://doi.org/10.23736/S0025-7826.17.03037-X

Francavilla G, Francavilla C. Physical exercise is therapy. MED SPORT 2013;66:625-8.

Francavilla C, Francavilla A, Braschi M, et al. Physical exercise and sport activities in patients with and without coronary heart disease. Monadi Arch Chest Dis 2007; 87-95.

Francavilla C, Vitale F, Ciaccio Marcello et al. Use of saliva in alternative to serum sampling to monitor biomarkers modification in professional soccer players. Frontiers in Phsiology, 2018. https://doi.org/10.3389/fphys.2018.01828

Gualniera, P., Scurria, S., Spagnolo, E.V., Sapienza, D., Asmundo, A. Post-cesarean necrotizing fasciitis caused by surgical site infection. 2017 . Gazzetta Medica Italiana Archivio per le Scienze Mediche. 176(10), pp. 565-569.

Maio, G.D., Monda, V., Messina, A., Villano, I., Francavilla, V.C. Physical activity and modification of lifestyle induce benefits on the health status. 2020 . Acta Medica Mediterranea. 36(3), pp. 19131919.

Mazzeo F, Motti ML, Messina G, et al. Use of nutritional supplements among south Italian students of Physical Training and Sport University. Current Topics in Toxicology. 2013 9:21-26.

Messina A, Bitetti I, Precenzano F, lacono D, Messina G, Roccella M, Parisi. et al. Non-Rapid Eye Movement Sleep Parasomnias and Migraine: A Role of Orexinergic Projections. Front Neurol. 2018 Feb 28:9:95. https://doi.org/10.3389/fneur.2018.00095

Messina A, De Fusco C, Monda V, Esposito M, Moscatelli F, Valenzano A, et al. Role of the orexin system on the hypothalamus-pituitary-thyroid axis. Front. Neural Circuits 2016. 10. https://doi.org/10.3389/fncir.2016.00066

Messina A, Monda V, et al. Role of the orexin system on arousal, attention, feeding behaviour and sleep disorders. Acta Medica Mediterr 2017. 33(4):645-64. https://doi.org/10.19193/03936384_2017_4_096

Messina G, Zannella C, Monda V, Dato A, Liccardo D, De Blasio S, et al. The Beneficial Effects of Coffee in Human Nutrition. Biol Med 2015.

Monda, V., Villano, I., Messina, A., Valenzano, A., Salerno, M., Signorelli, S. S., et al. (2019). Aerobic exercise and orexin A: Role of sympathetic activity and redox system. 33, 587-592.

Mondello, C., Cardia, L., Bartoloni, G., Asmundo, A., Ventura Spagnolo, E. Immunohistochemical study on dystrophin expression in CAD-related sudden cardiac death: a marker of early myocardial ischaemia. 2018 . International Journal of Legal Medicine. 132(5), pp. 1333-1339. https://doi.org/10.1007/s00414-018-1843-3 
Moscatelli F, Messina G, Valenzano A, Monda M, et al. Relationship between RPE and Blood Lactate after Fatiguing Handgrip Exercise in Taekwondo and Sedentary Subjects. Biol Med 2015.

Moscatelli F, Messina G, Valenzano A, Monda V, Viggiano A, Messina A, Petito A, Triggiani Al, Ciliberti MA, Monda M, Capranica L, Cibelli G. Differences in corticospinal system activity and reaction response between karate athletes and non-athletes. Neurological Sciences 2016. 37(12). https://doi.org/10.1007/s10072-016-2693-8

Patti A, Bianco A, Karsten B, Montalto MA, Battaglia G, et al. The effects of physical training without equipment on pain perception and balance in the elderly: A randomized controlled trial. Work 2017. 57:23-30. https://doi.org/10.3233/WOR-172539

Penna E, Cerciello A, Chamberry A, et al. Cystatin B Involvement in synapse physiology of rodent brains and human cerebral organoids. Front Mol Neurosci. 2019; 12:195. https://doi.org/10.3389/fnmol.2019.00195

Polito R, Monda V, Nigro E, Messina A, Di Maio G, Giuliano MT, et al. The important role of adiponectin and orexin-A, two key proteins improving healthy status: focus on physical activity. Front. Physiol. 2020 11:356. https://doi.org/10.3389/fphys.2020.00356

Spagnolo, E.V., Mondello, C., Cardia, L., aldino, G., Micali, A. Post-mortem immunohistochemical evidence of $\beta 2$-adrenergic receptor expression in the adrenal gland. 2019 International Journal of Molecular Sciences. 20(12),3065. https://doi.org/10.3390/ijms20123065

Sperandeo R, Maldonato MN, Messina A, Cozzolino P, Monda M, Cerroni F, et al. Orexin system: Network multi-tasking. Acta Medica Mediterr 2018. 34, 349-356. https://doi.org/10.19193/03936384 2018_2 55

Valenzano A, Polito R, Trimigno V, Di Palma A, Moscatelli F, Corso G, Sessa F, Salerno M, Montana A, Di Nunno N, Astuto M, Daniele A, Carotenuto M, Messina G, Cibelli G, Monda V. Effects of Very Low Calorie Ketogenic Diet on the Orexinergic System, Visceral Adipose Tissue, and ROS Production. Antioxidants 2019. 8(12). https://doi.org/10.3390/antiox8120643

Ventura Spagnolo, E., Mondello, C., Di Mauro, D., Alibrandi, A., Rizzo, G. Analysis on sarcoglycans expression as markers of septic cardiomyopathy in sepsis-related death. 2018. International Journal of Legal Medicine. 132(6), pp. 1685-1692. https://doi.org/10.1007/s00414-018-1840-6

Vicchio, T.M., Aliquò, F., Ruggeri, R.M., Cannavò, S., Ferraù, F. MicroRNAs expression in pituitary tumors: differences related to functional status, pathological features, and clinical behavior. 2020 Journal of Endocrinological Investigation. 43(7), pp. 947-958. https://doi.org/10.1007/s40618-019$\underline{01178-4}$

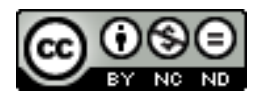

This work is licensed under a Attribution-NonCommercial-NoDerivatives 4.0 International (CC BY-NC-ND 4.0). 